\title{
O DISCURSO FUNDAMENTALISTA RELIGIOSO JUDAICO CRISTÃO ENQUANTO COMPONENTE DOS ESPAÇOS ESCOLARES PÚBLICOS VIVENCIADOS POR TRAVESTIS
}

\author{
André de Morais \\ Universidade Estadual de Ponta Grossa - UEPG \\ Programa de Pós-Graduação em Geografia \\ Doutorado em Geografia \\ andremorais.geo@gmail.com \\ Adriana Gelinski \\ Universidade Estadual de Ponta Grossa - UEPG \\ Programa de Pós-Graduação em Geografia \\ Doutorado em Geografia \\ drycagelinski@gmail.com
}

\begin{abstract}
RESUMO
O presente trabalho concentra-se no seguinte objetivo: compreender como o fundamentalismo religioso judaico-cristão utilizado enquanto instrumento de discurso, pode reforçar a opressão sofrida pelo grupo de Travestis nos espaços das escolas públicas. Como recorte espaço-escalar, utilizou-se de dois exemplos de cidades, média e grande, respectivamente, Ponta Grossa - PR e Maringá - PR. Busca-se evidenciar a influência do discurso religioso fundamentalista, experienciado pelo grupo de travestis residentes dos municípios em questão, que já ultrapassaram idade escolar e, por suposto, vivenciaram em algum momento de suas trajetórias de vida, a espacialidade da escola. Foram realizadas 10 entrevistas seguindo roteiro semiestruturado, sendo posteriormente transcritas, sistematizadas e analisadas. Dentre as evocações classificadas a partir de espacialidades e categorias discursivas, localizou-se a espacialidade escolar que, majoritariamente, se concentrou através da escola pública, instituição educacional que, em tese, tem por diretrizes, corresponder à laicidade estatal brasileira. Tal espacialidade aparece como uma das que representam mais desconforto por parte das travestis, estando permeada pelo discurso religioso que reitera o mecanismo de gênero alimentado por discursos binários, heterossexuais, ou seja, pelo processo sexualizador do pecado.
\end{abstract}

Palavras-chave: Fundamentalismo religioso. Escola. Transfobia. Espaço. Geografia da Religião.

\section{THE CHRISTIAN JEWISH RELIGIOUS FUNDAMENTALIST SPEECH WHILE COMPONENT OF THE PUBLIC SCHOOL SPACES EXPERIENCED BY TRAVESTIS}

\begin{abstract}
The present work concentrates on the following objective: understand how christian jewish religious fundamentalist used dircursive device can reforce the oppression suffered by the group of transvetites on the public school space. As a scalar-space clipping, we use two examples of cities; médium and large, respectively, Ponta Grossa - PR e Maringá - PR. We search evicendence the influence of the fundamentalist religious discurse experienced by the group of transvestites residents of the municipalities concerned who have passed school age an, by all means, have experienced at some point in their life trajectories, the spatiality of the school. Were realized 10 interviews following a semi-structured script, being later transcribed, systematized and analyzed. Among the evocations classified from spatiality and discursive categories, we found the school spatiality that, mainly, was concentrated through the public school, an educational institution that, in theory, has a guidelines, to correspond to the Brazilian state secularism. Such spatiality appear as one of the most discomfort on the part of transvestites, being permeated by religious discurse that reiterates the gender mecanism fueled by binary and heterossexual discourses, that is, by the sexualizing process of the sin.
\end{abstract}

Keywords: Religious Fundamentalism. School. Transphobia. Space. Religious Geography. 


\section{INTRODUÇÃO}

O fio condutor desta reflexão busca compreender como o fundamentalismo religioso judaico-cristão utilizado enquanto instrumento de discurso, pode reforçar a opressão sofrida por indivíduos que não correspondem à linearidade gênero - sexo - desejo (BUTLER, 2003) no espaço escolar, sobretudo de escolas públicas brasileiras. Para que esta reflexão torne-se exequível, estabeleceu-se diálogo com Travestis de Ponta Grossa - PR e Maringá - PR, que já vivenciaram em algum momento de suas trajetórias de vida o espaço escolar. A partir desta questão faz-se necessário apoiar-se em Massey (2008), que afirma que o espaço é resultante das relações sociais, esfera de multiplicidades e está em constante construção, ou seja, é dinâmico.

Pensando que a escola pode ser entendida como um espaço, o qual produz experiências, vivências, simbolismos positivos e negativos, bem como sentimentos de controle e desconforto, o espaço escolar, assim como os demais espaços, está envolto por múltiplos discursos, sendo um deles o discurso fundamentalista religioso judaico-cristão, cuja matriz norteadora se concentra na crença de uma 'verdade divina'.

O espaço escolar propõe uma vivência e está presente por diversos anos na vida das pessoas, contribuindo para a formação dos mesmos como sujeitos sociais. Nota-se que este espaço é de grande relevância na formação social, podendo deixar marcas positivas, como negativas na vida das pessoas. Destarte, este ensaio concentra-se na busca de evidenciar o fato de que as práticas homofóbicas não apenas são elementos subjetivos desse recorte espacial, como também, são grandes responsáveis pela marginalização de determinados sujeitos que o constituem.

A partir deste momento, busca-se evidenciar a influência do discurso religioso fundamentalista nas escolas públicas, experienciado pelo grupo de travestis do município de Ponta Grossa e Maringá PR. É de extrema importância o enlace de que ao decorrer desta reflexão, utiliza-se como fonte de dados entrevistas realizadas com travestis residentes nestes municípios até o momento em que foram acessadas e, deste modo, não necessariamente tiveram suas vidas pautadas de maneira integral nestas cidades e, portanto, nem sempre a realidade escolar vivenciada por estas travestis tem relação direta com as cidades em questão.

É relevante afirmar que os olhares assumidos a partir dos sujeitos pesquisadores deste artigo partem de uma perspectiva geográfica e, deste modo, visam colaborar para o escopo cientifico da Geografia e das Ciências Humanas de modo interdisciplinar, dado que somente nas duas últimas décadas, a ciência geográfica brasileira tem se voltado para análises referentes às particularidades dos sujeitos sociais, como gênero, sexualidades e, sobretudo, a relação destes conceitos com discussões sobre religião. Nogué e Romero (2006) constroem seus argumentos acerca da necessidade da ciência geográfica abordar em suas reflexões o 'invisível, o intangível e o efêmero'. Sendo assim, aqui busca-se corresponder a este anseio proposto pelos autores, bem como, colaborar para o enriquecimento teórico deste campo específico do saber.

Portanto, este trabalho propõe compreender a relação entre espaço escolar público, especificamente através de entrevistas realizadas com travestis residentes em Ponta Grossa e Maringá - PR, as vivencias e experiências dos indivíduos deste grupo e a influência do discurso religioso fundamentalista judaico-cristão em suas trajetórias, que caminha na contramão do dever estatal de imprimir em sua educação básica escolar uma realidade laica. Busca-se então, um diálogo entre conceitos discutidos na ciência geográfica, como o espaço, por intermédio das reflexões de Massey (2008); o gênero pensado por Butler (2003); bem como, utiliza-se Panasiewicz (2008), Boff (2009), Guimarães (2014), Kung (1993) e Karen Armstrong (2001) para refletirmos sobre o conceito de fundamentalismo religioso.

\section{REFLEXÕES SOBRE ESPAÇO ESCOLAR PÚBLICO, VIVÊNCIA TRAVESTI E O DISCURSO RELIGIOSO FUNDAMENTALISTA}

É necessário afirmar que apesar de não corresponderem todas as escalas a uma linearidade temporal ideal, fixa e imutável, atualmente a sociedade ocidental se localiza em uma época delimitada pelo estado líquido das relações sociais. Em diálogo com Bauman (2005), em "Identidade: Entrevista a Benedetto Vecchi", se pode afirmar que a sociedade líquido-moderna se reparte em fragmentos mal distribuídos e/ou coordenados, onde as individualidades do ser humano se dividem em efêmeros momentos fragilmente conectados e facilmente rompíveis. Neste caminho,

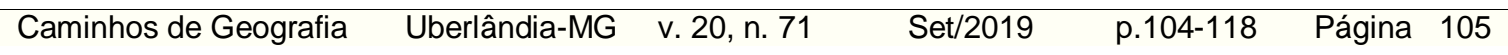


a identidade constitui-se enquanto um complexo marcador cultural individual, correspondendo às apreensões de realidade dos sujeitos através de suas interrelações e, destarte, de grupos. A identidade é resultante de intersubjetividades que, segundo Lima (2014): “(..) Dizem respeito, portanto, à consciência coletiva ou, mais precisamente, à maneira como um objeto é instituído em comum acordo com o grupo social." (LIMA, 2014. p. 34).

É factual que marcadores identitários podem se constituir singularmente a determinados grupos, como, por exemplo, a identidade nacional estadunidense, muito demarcada nas bandeiras expostas em frente às casas da população deste país. Isso não é de difícil imaginação ou observação em filmes hollywoodianos. O fato é que, concomitantes às singularidades dos estadunidenses que materializam sua manifestação nacional identitária através da bandeira do país, estão particularidades de outros grupos e/ou indivíduos. Destarte, cabe a afirmação de que as particularidades identitárias tangentes a determinados grupos ou indivíduos não constituem apenas a população deste país norte-americano, mas sim, correspondem a quaisquer sujeitos em suas mais diversas relações sociais.

$\mathrm{Na}$ conjectura entre o objetivo desta proposta, demarcado na introdução, e a reflexão estabelecida nos dois parágrafos supracitados, faz-se necessária à afirmação de que dentre os diversos possíveis marcadores que vão de encontro às apreensões identitárias dos indivíduos, como raça, etnia, classe de renda, dentre outros, este artigo se concentra na identidade de gênero. Segundo Strey (1998) não se pode estabelecer o mesmo significado sobre gênero e sexo, pois o sexo é apreendido simbolicamente a partir das experiências sociais vividas através do gênero. Para Butler (2006) o gênero é resultante de diversos fatores produzidos a partir das relações sociais através do espaço. Assim, as inter-relações dos sujeitos sociais que, por sua vez, resultarão em ações repetitivas, darão inteligibilidade a determinados 'padrões' socioculturais que serão reafirmados e reproduzidos ao longo de uma historicidade não linear. Aqueles sujeitos não enquadrados nestes 'padrões' (leis científicas, sociais, entre outras), sofrerão segregação sócio-espacial.

As travestis, grupo foco desta reflexão, correspondem aos sujeitos cuja apreensão identitária não se delimita a partir desta matriz de 'normalidade'. Ainda em diálogo com Judith Butler (2003), cabe a constatação de que uma das práticas da sociedade ocidental atual concentra-se na linearidade dos corpos entre sexo, prática sexual, gênero e desejo. Sobre esta questão, Ornat e Morais (2014) afirmam:

(...) Todo corpo que não tem correspondência a esta característica linear, correspondência aos padrões estabelecidos de normalidade ou não normalidade heterossexual, é nomeado como desviante a partir dos mais variados qualificativos, produzindo o efeito da reprodução da normalidade e a manutenção de sua 'ordem natural'. O grupo que nos têm instigado é aquele justamente que tensiona esta ordem linear, questionando a ligação padrão heterossexual entre sexo, gênero, prática sexual e desejo. Este grupo se refere às travestis. (ORNAT e MORAIS, 2014. p. 1)

A partir do que Ornat e Morais (2014) definem enquanto tensão da ordem linear entre sexo, gênero, prática sexual e desejo, bem como, na noção de que sujeitos não enquadrados na matriz de 'normalidade' de leis científicas, sociais, dentre outras, sofrem segregação sócio-espacial, coloca-se o espaço escolar enquanto uma escala correspondente a esta lógica. No entanto, para uma discussão em torno desta questão, faz-se necessária uma explanação breve sobre o conceito de espaço. Armando C. Silva (1986) afirma que o espaço produzido é estruturado, espelhado/correspondido no processo no qual é produzido. Sendo assim, o espaço se organiza então segundo um modo de produção. Em contraposição, Joseli M. Silva (2000) argumenta que o espaço não resulta apenas das materialidades produzidas a partir do modo de produção capitalista, mas também é resultante dos simbolismos apreendidos a partir das relações sociais. Essa afirmação tem conjectura com Corrêa (1995), que afirma que o espaço é resultante das relações sociais, porém também é elemento fundamental para a manutenção destas mesmas relações.

Essas apreensões acerca do conceito de espaço têm relação direta com a disciplina central na qual este artigo está apoiado na elaboração da presente reflexão; a Geografia. É importante destacar que, embora não haja consenso em todas as frentes epistemológicas deste campo específico do saber sobre o significado do conceito, faz-se necessário localizar o que aqui se compreende a respeito. 
Neste caminho, é cabível estabelecer uma ligação com Doreen Massey (2008) que afirma que o espaço é resultante das relações sociais, está em constante mudança e é esfera de multiplicidades. Assim, o principal ponto de partida a respeito de 'espaço' no qual apoiamos este debate, consiste no diálogo que podemos estabelecer com Massey (2008), no qual se compreende o conceito enquanto não apenas 'resultante', porém a própria dinâmica e multiplicidade das relações sociais, ou seja, não enquanto somente o material ou somente as relações, mas enquanto uma matriz complexa instituída a partir dos sujeitos sociais e de suas vivências ou, como afirma a autora, uma 'soma de trajetórias', um espectro de 'estórias-abertas-até-agora'.

Diante do exposto, pode-se retornar à escala do espaço escolar. Assim como quaisquer outras escalas que podem ser apreendidas e representadas socialmente, a escola pode ser assumida enquanto espaço que, indefectivelmente se relaciona com outras escalas espaciais. Destarte, as relações sociais que constituem o espaço escolar produzirão simbolismos que não se separam das representações existentes em outras escalas da sociedade. Ao retornar à discussão assumida por Ornat e Morais (2014) em diálogo com Butler $(2003,2006)$, é possível a afirmação de que as tensões que resultarão na segregação sócio-espacial do grupo de travestis se perpetua no espaço escolar.

Parte das entrevistas realizadas e que constituem objeto desta pesquisa, foram realizadas por Gelinski em 2016, em um total de quatro entrevistas exclusivamente com travestis e transexuais residentes do município de Maringá - PR. Algumas das outras entrevistas que também servem de apoio para a realização desta reflexão foram realizadas por Morais em 2013, com nove travestis residentes no município de Ponta Grossa - PR. Para que essas entrevistas realizadas por Gelinski e Morais, nos anos de 2016 e 2013, pudessem constituir um eixo de reflexão acerca do objetivo deste trabalho, foram transcritas e classificadas através do método de Análise de Conteúdo, de Bardin (1977). Tal método possibilitou, respectivamente, enquanto resultado, 202 evocações (referentes às quatro entrevistas realizadas com o grupo de Maringá - PR) e outras 316 evocações (resultantes das entrevistas realizadas com o grupo de Ponta Grossa - PR).

Com relação à metodologia proposta neste artigo de 'Análise de Conteúdo', citada no parágrafo anterior, é importante o destaque de que análises das entrevistas consistem em transcrevê-las, buscando preservar os discursos dos sujeitos entrevistados, neste caso dois grupos de travestis residentes em cidades do Paraná e, posteriormente, localizar as categorias semânticas que constituem todo o trecho do texto resultante das transcrições. Este encaminhamento está relacionado ao 'desmembramento' dos excertos textuais, em unidades chamadas evocações que, sequencialmente, são reagrupadas nas chamadas 'espacialidades discursivas' e 'categorias discursivas', correlacionando-as segundo estes dois 'filtros' de classificação.

As 'categorias discursivas' se relacionam ao significado que cada evocação está atribuída, ou seja, ao sentimento 'produzido' pelo sujeito, às suas práticas, à sua memória. As 'espacialidades discursivas' remetem ao recorte espaço escolar onde a evocação e, por suposto, a 'categoria discursiva' se referem, posto que, há geografia em todo fenômeno onde há dispersão espacial (GOMES, 2014).

No que se referem às evocações analisadas, a partir do trabalho pela autora (2016) e pelo autor (2013), os excertos textuais provenientes das entrevistas foram classificados em 11 espacialidades discursivas constituídas pelas travestis entrevistadas. Dentre as evocações classificadas a partir de espacialidades e categorias discursivas, localizou-se a espacialidade escolar. Ao estabelecer um resgate no acervo documental do Grupo de Estudos Territoriais - GETE/UEPG foram identificadas apenas quatro evocações relacionadas à escola. Inicialmente, se forem comparadas o número total de evocações com o número de apenas quatro evocações referentes à espacialidade da escola, levanta-se o questionamento de que possivelmente isso está relacionado à ausência das travestis nesta espacialidade. Por segundo, as categorias discursivas que relacionam as evocações das travestis entrevistadas à espacialidade escolar, correspondem a 'relações de exclusão', com duas evocações, 'relações de diferença' e 'relações de não aceitação'.

As falas que tratam de maneira específica à exclusão sofrida pelo grupo se destacam das demais ao apresentarem a justificativa da não conclusão da educação básica ainda em período de idade escolar. As duas falam se localizam a partir da mesma travesti que, ao decorrer da sua fala, relata experiências de violência de gênero de maneira multiescalar, significados na espacialidade da casa, em que residia com sua família e que, se estendia à escola, onde estabelecia relações com colegas. A maneira como sua trajetória foi significada com estigmas resultantes da violência, 
Evidencia-se que o discurso fundamentalista religioso cristão não se restringe apenas ao espaço igreja, mas perpassa todos os espaços, influenciando assim as relações sociais, os discursos normativos e as condutas 'pecaminosas' ou não. Panasiewicz (2008), de modo semelhante a Armstrong (2001), ressalta que o termo fundamentalismo pode ser caracterizado por atitudes fanáticas de pessoas. Ademais, o termo fundamentalismo nos últimos anos cada vez mais vem ganhando força na sociedade, perpassando os mais variados espaços como da educação, da política, da saúde e da economia "carregando consigo um traço claramente ideológico" (PANASIEWICZ, 2008, p. 3).

Assim como em outros recortes espaciais, a escola tem especificidades (que se inter-relacionam com outras escalas), possuindo o papel de ensino - aprendizagem, porém em decorrência do que já afirmamos das escalas se cruzarem, também é carregada de experiências, diferenças e desigualdades. $\mathrm{Na}$ escola as pessoas que não seguem a norma ou são distintas das demais pessoas vivenciam determinadas divisões e restrições. Assim, o espaço escolar está envolto pelo discurso religioso fundamentalista embasado em uma verdade divina, a qual através de múltiplos mecanismos de classificação, ordenamento, hierarquização determina práticas para 'alimentar' a norma. A escola, além de criar códigos e vários sentidos para as pessoas, 'dita' o habitus (BOURDIEU, 2008) de cada indivíduo, os espaços e os modelos a serem seguidos. Como, por exemplo, apoiando-se em formas singulares de vocabulário, passagens bíblicas, as santas, crucifixos e ritos presentes até os dias atuais em algumas destas instituições, que ferem diretamente a configuração laica, tal qual o Estado tem como obrigação sua garantia.

Pensando assim, é possível compreender nas relações sociais elementos que vão influenciar certas decisões, divisões tanto espaciais, como comportamentais, entre as pessoas, como é o caso do preconceito homofóbico/transfóbico. Esse elemento enquanto um agente comportamental vai regular, condicionar ou até desconectar as relações entre as pessoas heterossexuais e homossexuais, colocando-os em diferentes posições espaciais, ora sendo centro e em outra margem (Hanke et al., 2015). Essa afirmação converge no que Arcturus demonstra através a sua fala, acerca da marginalidade e centralidade segundo as relações que estabelece( $u$ ) ao longo de sua vida, como as relações de tensão na escola e na casa da família e as relações de aliança quando estabelecida com outras travestis:

\begin{abstract}
Então eu fiquei na escola até a oitava série né, aguentei até a oitava depois não consegui mais. Daí eu peguei e comecei a conviver com elas (outras travestis) e daí eu peguei e fui vendo entendeu. Como que eu podia ser, como que eu podia andar. Ai nas ruas foi nas ruas que eu tive mais liberdade entendeu, (...) quando eu tava dentro da casa da minha mãe eu morava junto com ela né, eles eram evangélicos entendeu. Ela aceitava mais só que também não aceitava, entendeu. E na época que eu era transformista que era Dragqueen, daí ela assim... ela não aceitou, entendeu. (Entrevista realizada com Arcturus, em Maringá, em 21/07/2014).
\end{abstract}

Portanto, tais atitudes convergem no que Hanke et al. (2015) afirmam acerca da marginalização/centralização de corpos e, o que para Louro (2004) se coloca como exclusão/inclusão, onde algumas marcas que sujeitos carregam em seus corpos contribuem para pertencerem ou não a determinados espaços, sendo respeitados, tolerados ou rejeitados. Por exemplo, o corpo de Arcturus, enquanto estava como homem gay (não assumido) foi tolerado, mas como Dragqueen/travesti foi privada de vivenciar espaços como casa da família, escola e igreja. Passando por constrangimentos de olhares, julgamentos, situações desconfortáveis criando assim limites na vivência sócio-espacial. Tal desconforto justificado pelo fundamentalismo religioso que corrobora em discursos, presentes na escola e em uma família de fé cristã protestante, é um tensionamento portanto na vida de Arcturus e de outros indivíduos que constituem o grupo.

Sendo assim, Louro (2004) relata que socialmente e culturalmente essas formas de pensar sexo e sexualidade são constantemente inseridas em nosso cotidiano, através de práticas e de discursos envoltos de tradicionalismos e frequentemente fundamentado em uma única verdade. E corpos que não seguem a 'verdade' ou não estão inseridos na normalidade são vistos como pecadores e desviantes não sendo merecedores de estar e ocupar determinados espaços como a escola. 
O termo 'fundamentalismo' não é perfeito, mas rotula um conjunto de movimentos, que mesmo distintos, possuem considerável semelhança. A partir das afirmações realizadas por Marty e Appleby (1991), a autora afirma que os 'Fundamentalistas' obedecem, de certa forma, a um padrão. Defendem e realizam maneiras de espiritualidade que são combativas, surgindo como a resposta de alguma crise. Enfrentam um conjunto de pessoas que são consideradas como inimigas, cujas crenças e políticas seculares são contrárias às práticas religiosas. Mais além, estas lutas não são vistas como sendo meros embates políticos, mas enquanto uma batalha cósmica entre forças do bem e do mal. Frente a uma possível "aniquilação", protegem sua identidade, fortificam sua identidade segundo doutrinas e práticas do passado. Evitando uma "contaminação" cultural, se afastam da sociedade, elaborando uma contracultura.

Desta forma, Souza (2010, p. 12) explana que a "cosmovisão fundamentalista permite que os sujeitos sociais evoquem, sempre que necessário, conceitos "fundamentais", legitimando posturas conservadoras em face dos conflitos internos". Assim:

O fundamentalismo é uma forma fanática e neurótica de religiosidade, em que a forma específica de teoria e prática religiosas que é abraçada torna-se uma espécie de 'último refúgio' do indivíduo contra forças espirituais maléficas que o querem destruir. Estas forças maléficas encarnam-se, ora na ciência moderna, ora no humanismo, ora na reflexão crítica, ora na consciência sócio-política e econômica, ora na arte, ou em qualquer coisa ou ideia com a mínima aparência de novidade, pois o fundamentalismo é sempre 'quenofóbico' (do grego Kainos, isto é, 'novo'). (ORNELAS, 2003 p. 37)

Ao pensar a respeito do protestantismo no Brasil, com cerca de 42,3 milhões de fiéis no país, o que representava 22,2\% pelo censo de 2010 (IBGE) e 27\% segundo Latinobarómetro (2017). É possível notar o crescente discurso sectarista e preconceituoso, o qual segundo Gouvêa (2006, p. 42) "tornou-se uma fábrica de seitas" com discursos de ódio, intolerância e violência de gênero. Ou, como nas palavras do autor:

(...) As igrejas evangélicas se mostram não somente despreocupadas com a defesa das mulheres e das minorias, mas antes mostram-se elas mesmas opressoras das mulheres e das minorias, como se evidencia claramente pela recusa fundamentalista em permitir às mulheres aquilo que é seu direito biblicamente sancionado, de exercer plenamente o ministério pastoral, e de participar em condições de igualdade com os homens da liderança e de todas as atividades educacionais e administrativas das igrejas (GOUVÊA, 2006, p.42).

Os sermões e a 'palavra' constantemente passada pelas lideranças religiosas, através dos momentos de culto e reunião religiosa, as reflexões nos grupos de estudos bíblicos e as práticas religiosas reforçam a ideia de ficções de feminino e masculino, certo e errado, pecado e não pecado, instituindo, assim, um processo sexualizador do pecado. Tais lideranças religiosas crêem e vivem em função do serviço da verdade, tendem a impor sua visão de tradição como único caminho, única ortodoxia e assim alimentam o poder religioso. Fica evidente nesses espaços a busca constante dos espaços de poder, por meio de discursos, normas inquestionáveis com penas anexas para as pessoas que transgridem, sendo alvo dos "grupos de controle e denúncia que, instauram um verdadeiro clima de regime" (CIPRIANI, 2015) de controle dos corpos.

Este processo está diretamente ligado aos discursos homofóbicos e de opressão em relação às sexualidades. "A identificação do sentimento de total adesão de fé ao absoluto de Deus e a acolhida da sua auto-revelacão levam muitos crentes a assumir posturas rígidas de defesa de sua profissão religiosa e comportamentos intolerantes" (CIPRIANI, 2015).

Desta forma, as compreensões fundamentalistas reiteram a heterossexualidade como criação divina, indo contra a diversidade sexual. Pois acreditam que as pessoas LGBT são pessoas desviantes, doentes e impuras. Ora, deste modo, o discurso fundamentalista conservador atua de modo a domesticar os corpos (Souza, 2010), como uma das lideranças religiosas entrevistadas nos demonstram através do seguinte trecho: 
E aí a homossexualidade, os LGBT, dentro da bíblia também são muito demonizados e ainda tem esse respaldo machista, né o machismo ajuda imperar muito essa discriminação com LGBT porque ela demoniza demais a sexualidade, o sexo na bíblia é como se eu fosse dizer assim, é genitalizaram o pecado, o pecado ficou na área genital, então você lê a bíblia primeira coisa pecado é sexo. Então quando se fala em homossexual a palavra já se tem a pronuncia de sexo na palavra eles já interpretam como pecado, né. Aí a interpretação errada, as pessoas pegam a bíblia interpretam do jeito que quer, e demonizam gays. (Entrevista realizada com liderança religiosa ICM-Maringá, Maringá, em 30/01/2016).

Neste sentido, o processo sexualizador do pecado é alimentado pela reiteração da linearidade sexo, gênero e desejo, como proposto por Butler (2003), perpassando todos os espaços cotidianos. Natividade e Oliveira (2009, p. 10) ressaltam que os embates de grupos excluídos dos espaços religiosos como a comunidade LGBT são constituídos por inúmeras frentes, "onde se armam os combatentes com a inevitável carga de exasperação e sofrimento". Tais embates ocorrem em resposta ao processo sexualizador do pecado, pois de um lado estão os grupos cristãos que defendem e reiteram a heterossexualidade como norma, sendo vista como única prática moral e bem vista aos olhos de Deus.

Ao analisar as sexualidades, compreende-se que esta vivência social, que também é identitária, faz parte de um emaranhado de discursos e práticas, podendo ser individuais ou coletivas. Assim, tanto a ideia de gênero como a noção de sexualidades é um ato performativo, como propõe Butler (1990, p.15), pois "são palavras e gestos que, ao serem expressos, criam uma realidade" (PORCHAT, 2010, p. 2), passando através dos discursos, a ser uma 'verdade' e, com uma constante frequência de repetições, cria-se a noção ilusória e binária de papéis e práticas direcionadas ao gênero e às sexualidades.

Tais práticas e discursos são desenvolvidos por compreensões teológicas fundamentalistas, as quais compreendem os textos bíblicos como uma verdade absoluta. Assim há certa resistência por parte dos fundamentalistas em reconhecer leituras de maneira histórico-crítica ou hermenêutica, bem como questionamentos em relação aos textos bíblicos, sendo vistos, assim, como uma afronta. "A religião, sob essa perspectiva, aparece como o lugar do controle e da regulação, e a sexualidade como um domínio livre de amarras institucionais e sociais" (NATIVIDADE, 2008, p. 140). Por sua vez, a religião reforça aquilo que Natividade e Oliveira (2009) denominam enquanto homofobia pastoral/religiosa. Para os autores, a homofobia pastoral/religiosa está relacionada a um:

\begin{abstract}
Conjunto de práticas que opera por meio de táticas plurais de desqualificação e controle da homossexualidade. A homofobia religiosa não se manifesta somente ao nível de percepções e juízos morais pessoais ou coletivos, mas envolve formas de atuação em oposição à visibilidade e reconhecimento de minorias sexuais. É conveniente estabelecer uma distinção analítica, entre um uso de discursos religiosos na esfera pública que é voltado mais diretamente à obstrução de direitos LGBT, e formas de homofobia religiosa que se dão na esfera do cuidado pastoral, na interação entre lideranças e fiéis ou no controle mútuo que os fiéis estabelecem entre si. Esta homofobia pastoral se revela nos relatos de gays, lésbicas e travestis com passagem por religiões cristãs, assim como em alguns documentos produzidos como guia são exemplos normativos para a conduta dos fiéis e as atividades pastorais, podendo manifestar-se explicitamente ou de formas mais sutis. (NATIVIDADE e OLIVEIRA, 2009, p. 6).
\end{abstract}

Como exemplo, se pode citar um ocorrido no dia 22 de junho de 2015, sob recinto da Câmara Municipal do município de Ponta Grossa - PR que, por meio de sessão extraordinária, aprovou o projeto de lei que propõe a retirada das discussões sobre gênero e diversidades do Plano Municipal de Educação. Enquanto um fato, este episódio delimitou-se enquanto um momento de pressão por meio de grupos religiosos de matriz judaico-cristã em relação ao poder legislativo, cuja realidade concentra-se em alguns representantes (vereadores) cuja vivência está relacionada à práticas norteadas pelo protestantismo e catolicismo. Este é um exemplo localizado, porém, ao ser relacionado com os conceitos até aqui abordados, corrobora para a conclusão de que práticas sociais não se desprendem de espacialidades, ou seja, são carregadas de culturalidades e de valores tangentes à determinados grupos que, de sem dúvidas, colaboram para a exclusão/marginalização de corpos não heteronormativos de maneira cruel. 
Pode-se assim demonstrar que a exclusão de discussões tangentes à particularidades representacionais/identitárias em torno do espaço escolar, apenas corrobora para a marginalização de sujeitos que culturalmente são enquadrados enquanto corpos abjetos (BUTLER, 2006) e, destarte, na opressão destes sujeitos sociais. Tal característica deve ser apoiada na Constituição Federal de 1988, que garante a laicidade do Estado e, por suposto, de seus aparatos - como a Educação Pública, como demonstra o art. $5^{\circ}$, parágrafo VI, deste mesmo documento: "É inviolável a liberdade de consciência e de crença, sendo assegurado o livre exercício dos cultos religiosos e garantida, na forma da lei, a proteção aos locais de culto e a suas liturgias" (BRASIL, 1988). Se, por um lado, este parágrafo assuma a liberdade de crença e consciência da população brasileira, o parágrafo VIII do mesmo artigo, corrobora na noção de que nenhum indivíduo deve ser desprovido de direitos somente pela crença religiosa, convicção filosófica ou política. Ainda, o parágrafo seguinte (IX) traz: "É livre a expressão da atividade intelectual, artística, científica e de comunicação, independentemente de censura ou licença". O demonstrativo dos parágrafos presentes na Constituição Federal só confirmam que, além de ilegítimo o projeto de lei apresentado no município de Ponta Grossa e, além de outros projetos apresentados em outras escalas da Federação, é de um dano irreparável para a população quando da garantia do bem estar social.

Em suma, é um fato que a geografia por muito se preocupou com fatos 'visíveis' e facilmente cartografáveis e com isso, se explica a dificuldade de se trabalhar com fenômenos objetivados enquanto não 'materiais', ou seja, invisíveis, intangíveis e efêmeros. Definitivamente a globalização caracteriza-se pela invisibilidade, onde o poder é cada vez mais invisível e menos identificável. E é assim com a intangibilidade, ou seja, da não possibilidade de 'tocar, sentir materialmente' determinado objeto. Quanto à efemeridade, é um fato que se concordar com a conjectura proposta pelos autores em Bauman (2005), vivemos em uma era 'líquida', ou seja, se para a geografia, apreendemos o espaço enquanto resultante das relações sociais, significamos que as relações humanas também estão cada vez mais em processo de 'liquidificação'.

\section{VIVÊNCIAS E EXPERIÊNCIAS DAS TRAVESTIS DE PONTA GROSSA E MARINGÁ, PR NO ESPAÇO ESCOLAR}

Como brevemente explanou-se na seção anterior, o grupo que se relaciona de maneira direta a essa reflexão é o de travestis que já tiveram em suas trajetórias o componente do espaço escolar e, por suposto, a influência negativa direta do discurso fundamentalista religioso enquanto instrumento de opressão. A tabela 1 destaca, de maneira bastante sintetizada, as principais características das participantes deste processo de pesquisa - as travestis, que foi possível de ser elaborado a partir do primeiro momento de entrevistas: tornando-se repetitivas.

Tabela 1 - Perfil das travestis de Maringá e Ponta Grossa, PR.

\begin{tabular}{|c|c|c|c|c|c|c|c|}
\hline NOME & IDADE & ESCOLARIDADE & ETNIA & PROFISSÃO & RENDA & RESIDE & $\begin{array}{c}\text { AUTO- } \\
\text { IDENTIFICAÇÃO }\end{array}$ \\
\hline Arcturus & 24 anos & $\begin{array}{c}\text { Fundamental } \\
\text { Incompleto }\end{array}$ & Negra & $\begin{array}{c}\text { Não } \\
\text { Trabalha }\end{array}$ & $\begin{array}{l}\text { Sem } \\
\text { renda }\end{array}$ & $\begin{array}{c}\text { Casa } \\
\text { Missão }\end{array}$ & Travesti \\
\hline Veja & 27 anos & Médio incompleto & Negra & Cabeleira & $\begin{array}{c}1 \\
\text { Salário } \\
\end{array}$ & $\begin{array}{c}\text { Casa } \\
\text { Missão }\end{array}$ & Travesti \\
\hline Alpha & 27 anos & $\begin{array}{c}\text { Superior } \\
\text { incompleto }\end{array}$ & Branca & $\begin{array}{c}\text { Não } \\
\text { Trabalha }\end{array}$ & $\begin{array}{c}1 \\
\text { Salário } \\
\end{array}$ & Alugada & Transexual \\
\hline Betelgeuse & 22 anos & Médio incompleto & Negra & $\begin{array}{c}\text { Não } \\
\text { Trabalha }\end{array}$ & $\begin{array}{c}\text { Sem } \\
\text { renda }\end{array}$ & $\begin{array}{c}\text { Casa } \\
\text { Missão }\end{array}$ & Travesti \\
\hline Verde & 40 anos & $\begin{array}{l}\text { Médio Incompleto } \\
\text { (em curso) }\end{array}$ & Branca & Prostituição & $\begin{array}{c}3 \\
\text { Salários } \\
\end{array}$ & $\begin{array}{c}\text { Casa } \\
\text { Própria }\end{array}$ & Travesti \\
\hline Anil & 35 anos & $\begin{array}{l}\text { Médio Incompleto } \\
\text { (em curso) }\end{array}$ & Negra & Cabelereira & $\begin{array}{c}3 \\
\text { Salários }\end{array}$ & Alugada & Travesti \\
\hline Violeta & 55 anos & $\begin{array}{l}\text { Fundamental } \\
\text { Incompleto }\end{array}$ & Branca & Aposentada & $\begin{array}{c}1 \\
\text { Salário } \\
\end{array}$ & $\begin{array}{c}\text { Casa } \\
\text { Própria }\end{array}$ & Travesti \\
\hline Azul & 35 anos & $\begin{array}{l}\text { Médio Incompleto } \\
\text { (em curso) }\end{array}$ & Branca & Manicure & $\begin{array}{c}3 \\
\text { Salários } \\
\end{array}$ & Alugada & Transexual \\
\hline Vermelho & 60 anos & $\begin{array}{l}\text { Fundamental } \\
\text { Completo }\end{array}$ & Branca & Aposentada & $\begin{array}{c}1 \\
\text { Salário }\end{array}$ & $\begin{array}{c}\text { Casa } \\
\text { Própria }\end{array}$ & Travesti \\
\hline Amarelo & 20 anos & Médio Incompleto & Branca & Prostituição & $\begin{array}{c}3 \\
\text { Salários } \\
\end{array}$ & Pensão & Travesti \\
\hline
\end{tabular}

Fonte - Os autores (2018). 
Pensando que as sexualidades são ao mesmo tempo prática e discurso, compostas por "uma complexa malha de regulações que abarcam distintos saberes e poderes, incluindo o religioso" (NATIVIDADE, 2006, p. 2), pode-se compreender as sexualidades como um constructo social (HEILBORN, 2002). Desta forma, as vivências das travestis que compõem essa pesquisa constituem as categorias identitárias, bem como contribuem na compreensão de condutas, no "trânsito por distintos mundos sociais, incorporando ou rejeitando argumentos e noções provenientes de distintas visões de mundo" (NATIVIDADE, 2008, p. 4).

De modo geral, as pessoas entrevistadas têm idade entre 20 e 60 anos. Dessas, nenhuma pessoa tem ensino superior completo, sendo que apenas uma iniciou o ensino superior, no entanto, não concluiu devido à o que ela afirma serem as circunstâncias da vida e a necessidade de trabalhar, visto que mora de aluguel e no momento da entrevista estava afastada dos pais, buscando se estabilizar emocionalmente e financeiramente.

Seis não concluíram o ensino médio, uma pessoa tem o ensino fundamental completo e duas pessoas não concluíram o ensino fundamental. Dentre estas dez pessoas, seis se consideram brancas e, as outras quatro, reconhecem-se como negras. Oito entrevistadas consideram-se Travestis e duas Transexuais (embora, se incluem na pesquisa, pois ainda consideravam-se no momento das entrevistas como 'em transição'). A respeito da ocupação profissional, três membros do grupo entrevistado estavam trabalhando na mesma 'missão voluntária' relacionada à instituição religiosa à qual tinham ligação, duas se declararam cabelereiras, uma como manicure, duas aposentadas e outras duas com práticas relacionadas à prostituição. A faixa de renda correspondente o grupo varia entre nenhum rendimento até 3 salários mínimos. Outro ponto que vale destaque é que, três residem em uma Casa voluntária, três estabelecem residência em local alugado, três possuem casa própria e apenas uma reside em uma pensão. Vale destacar que duas das quatro primeiras listadas no quadro acima destacado, duas identificaram também como profissionais do sexo e, as das outras seis listadas, embora apenas declarem como principal atividade a prostituição, todas ainda constituem territórios de prostituição. Deste perfil enquadrado, duas travestis afirmam que, antes de residir na Casa da Missão, eram moradoras de rua, bem como, outras Essas duas, antes de conhecerem a casa da Missão, moravam na rua, bem como outras quatro pessoas entrevistas em algum momento de suas trajetórias já tiveram suas realidades marcadas enquanto moradoras de rua, como pode ser evidenciado no excerto seguinte:

Caí nas droga, caí no crack, fui pra prostituição, daí minha família, minha mãe mesmo principalmente, ela pegou e tipo olhava pra mim e falava assim você não tem mais jeito. E eu que queria, eu que queria ir pra prostituição, eu que queria ir pras drogas, eu ficava três, quatro dia sem ir embora só usando drogas. (Entrevista realizada com Veja, Maringá, em 20/01/2016).

Vale ressaltar que todas as pessoas entrevistadas nasceram e cresceram sob matrizes religiosas fundamentalistas judaico-cristãs e, tal condição foi suprimida a partir da tensão entre suas identidades, sobretudo correspondentes ao gênero e sexualidades.

Desta forma, essas pessoas vivenciam conflitos entre sua sexualidade, seu desejo, seu sentimento afetivo não heteronormativo e o discurso sexualizador do pecado. Há, assim, o "interdito religioso às práticas homossexuais" (NATIVIDADE e OLIVEIRA, 2009, p. 8), que se traduz em práticas/atos cotidianos, nas mais diversas escalas espaciais compostas pelos sujeitos e que, se alimentam de discursos fundamentalistas religiosos, tais como a escola. Ao publicizar a orientação sexual ou a identidade de gênero dissidente, automaticamente sentem a homofobia religiosa/pastoral, indo de olhares, comentários e discursos, até aos processos de 'cura e libertação' ou às expulsões de suas respectivas famílias, círculos sociais e espaço escolar.

Acerca desta última espacialidade, a escola, ela se apresenta como a terceira mais evidenciada pelas Travestis com $33 \%$ da concentração das evocações. Fato é que, como demonstramos ainda na seção anterior a respeito das falas que compreendem o espaço escolar a partir do grupo entrevistado por Morais e que, em relação ao grupo entrevistado por Gelinski , acarreta nessa somatória que eleva a espacialidade à condição de terceira mais elencada pelo grupo, a maioria do que se traduz enquanto significado para o grupo, sobre a espacialidade escolar, é o desconforto ocasionado a partir do confronto de identidades dissidentes da heteronormatividade com aqueles sujeitos que correspondem de maneira hegemônica a essa estrutura opressora, que as exclui ainda durante o período considerado de idade escolar, da possibilidade de acessar a escola e, por 
suposto, níveis de formação que as qualificam inclusive profissionalmente e que, destarte, tem ligação direta ao desemprego, o envolvimento das mesmas com a prática de prostituição e, até mesmo, com a condição de moradoras de rua.

Diante disso, as categorias discursivas, ou seja, a semântica produzida a partir das falas, que se relacionam à espacialidade da escola que, cabe reforçar, foi majoritariamente caracterizada por instituições públicas de ensino, tem correspondência direta aos processos de reconhecimento de identidade destas pessoas e, sucessivamente de exclusão por tais identidades serem subversivas à norma. A figura 1, por exemplo, pode destacar as porcentagens relativas às apreensões das travestis entrevistadas por Gelinski, em 2015, a respeito da escola:

Figura 1 - Relação entre Categorias Discursivas e a espacialidade da escola.

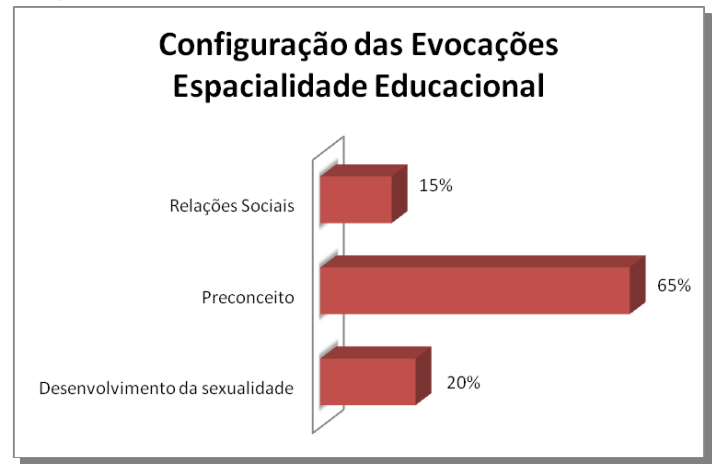

Fonte - Os autores (2018)

Evidencia-se, então, pelo grupo entrevistado, a espacialidade educacional como uma espacialidade de relevância no processo de descobrir, reconhecer e assumir as suas sexualidades, isto é, esta espacialidade faz-se presente no desenvolvimento das sexualidades dos indivíduos.

Contudo, o processo de desenvolvimento da sexualidade é marcado de forma negativa, com olhares, piadas e exclusões, visto que as pessoas LGBT carregam em seus corpos marcas lidas e interpretadas como 'erradas'/fora da norma (LOURO, 2004). Tais marcas vão contribuir para a exclusão em alguns espaços e em outros tolerados.

Ao compreender que o espaço educacional está presente nas vivências das pessoas por vários anos, desde a infância até a fase adulta, destaca-se, então, a relevância desta espacialidade, que está envolta por inúmeras relações e concepções, as quais contribuem, sobretudo, para as experiências das pessoas, uma vez que também é constituída por discursos normativos. Santos (2016) evidencia a espacialidade educacional como uma espacialidade permeada por conflitos e tensões, quando observada pelo viés da categoria identitária sexualidade.

Mostra-se assim a espacialidade escolar não somente como um espaço de ensino - aprendizagem, visto que esta espacialidade vai além, produz experiências, diferenças e desigualdades. No espaço educacional as pessoas que não seguem à norma ou são distintas dos/as demais alunos/as vivenciam determinadas divisões e restrições. Tal espaço, além de criar códigos e vários sentidos para as pessoas, 'dita' o que cada pessoa pode ou não pode, os espaços, os modelos a serem seguidos. Logo, a categoria discursiva 'Preconceito' é evidenciada pelas travestis com $65 \%$ do total de todas as evocações:

Pra ser em tudo e não tem, a maioria é cabeleireira que eles abrem até mais um espaço, mas nem todas têm o dom e têm a vontade de ser aquilo. A gente quer estudar sabe, quer ser estudada. Mas e aí na escola, falando de escola a travesti, a transexual, a transgênero em si, ela foge da escola por causa do preconceito na escola, é muito grande assim. Sempre tem o grupinho ou professor mesmo é muito ruim e como que vai estudar assim? Como vai aguentar? (Entrevista realizada com Alpha, Maringá, em 07/06/2016).

Tal fala coaduna com Louro (2004), ao relatar que socialmente e culturalmente as formas de pensar o gênero e a sexualidade são constantemente inseridas em nosso cotidiano, através de práticas e discursos, os quais estão envoltos de tradicionalismos e frequentemente fundamentado em uma única verdade (PANASIEWICZ, 2008). 
Ademais, a espacialidade educacional é uma das primeiras espacialidades vivenciadas por adolescentes e jovens, sendo constituída pelas relações sociais e pelas concepções apreendidas. É nela que se formam as amizades, as trocas e as concepções de mundo, assim a categoria 'relações sociais' é a terceira mais evocada pelas Travestis. Por outro lado o espaço esta permeado por um conjunto de práticas e discursos que reiteram a heterossexualidade como norma, contribuindo para a exclusão e o sentimento de desconforto presente na tal. O trecho, a seguir, referente à fala de Alpha, relata a experiência no espaço escolar, mostrando que em todo o período que estava na escola foi tratado no masculino, evidencia também a dificuldade de alterar o nome no histórico escolar e a importância de iniciar em outros espaços educacionais com o nome social:

Então, no meu caso como eu estudei sempre foi o João, nunca disse que tinha vontade de ser chamada de Iris ou Joana, era bem estranho tipo eu pensava mais quem é esse João. E tipo, então, não tem como eu voltar lá atrás isso não muda. Com os boletins tá João, tá tudo João. Eu vou mudar o que lá? Na escola não tem como, né, pra mim no meu caso não tem como. Mas se a pessoa já entra na faculdade tem como já começar com o nome já? Já é muito bom, é diferente porque é um direito seu, lá atrás, você não pode mudar, mas pelo menos o que já tá lançado é boletim é tudo, então já pelo menos na faculdade assim é importante. (Entrevista realizada com Alpha, Maringá, em 07/06/2016).

Comprova-se que a espacialidade educacional está envolta por uma complexa cadeia de relações e inter-relações, vivências e práticas específicas, como afirma Massey (2008). Contribuindo também para a formação das identidades das pessoas (ROSE, 1999). Indo além, a mesma espacialidade pode despertar sentimentos, deixando as mais variadas marcas nas pessoas.

Em vista disso, ao observar a espacialidade escolar como um leque de relações e informações, é possível compreender também que as relações e experiências vivenciadas nesta espacialidade estão diretamente ligadas com as categorias identitárias das pessoas e, tal dinâmica, constitui trajetórias afirmadas enquanto legítimas em detrimento de outras sendo, por exemplo, as identidades significadas pelas travestis que constituem essa pesquisa, lócus de tensão para estas pessoas que, por suposto, significam exclusão/marginalização nesta escala (e naquelas que se inter-relacionam).

Nestes termos, de acordo com o exposto a partir das entrevistas realizadas com as travestis em questão, em conjunto com a teoria apresentada, que corrobora com o afirmado acerca da marginalização/exclusão deste grupo em determinadas escalas da cidade, evidenciou-se que o espaço escolar tem grande relevância em suas trajetórias de vida. Os excertos textuais demonstram que essa espacialidade é constantemente evocada quando o grupo assume significados em torno de suas sexualidades e gênero, no processo de identificar-se e sua relação. Para além, demonstram que esse processo de identificação, por não corresponder à matrizes hegemônicas que localizam as pessoas no centro das relações sociais e, portanto, nas espacialidades que instituem, funciona com um forte estratificador social (BAUMAN, 2005) e, é na escola que isso é demarcado de maneira extremamente marcante para as vivências das travestis, pois apreende esta espacialidade como desconfortável/degradante.

Demonstrou-se então, que o discurso fundamentalista religioso judaico cristão é um forte instrumento para justificar a marginalização/exclusão espacial das pessoas que constituem essa pesquisa enquanto entrevistadas, sobretudo na escola, pois reforça a matriz heteronormativa a partir de condutas que se estabelecem segundo interpretações de livros considerados sagrados, como a bíblia e, por sua vez, reproduzidos com teor preconceituoso homofóbico/transfóbico (e de outras formas, porém não listadas aqui). Tal consideração revela que, muito embora a Constituição ampare as instituições públicas e as práticas estatais enquanto laicas, é através deste fundamentalismo enraizado nas entranhas do poder, que ocorrem as mais diversas dinâmicas sociais e, em decorrência disso, a vida de determinados sujeitos, como as travestis, são estigmatizadas como corpos de que não importam (Butler, 2003), indo na 'contramão' das garantias das pessoas enquanto cidadãs (independentemente de representações identitárias).

\section{CONSIDERAÇÕES FINAIS}

Este trabalho teve como fio condutor compreender como o fundamentalismo religioso judaico cristão utilizado enquanto instrumento de discurso, pode reforçar a opressão sofrida pelo grupo de

$\begin{array}{lllll}\text { Caminhos de Geografia } & \text { Uberlândia-MG } & \text { v. 20, n. } 71 & \text { Set/2019 } & \text { p.104-118 }\end{array}$ Página 115


travestis nos espaços das escolas públicas, utilizando-se como recorte espaço-escalar a experiência de travestis entrevistadas em Ponta Grossa e Maringá, Paraná. Neste sentido a escola pode ser entendida como um espaço de múltiplas experiências e sentimentos, os quais podem ser levados para a formação de cada pessoa.

Neste contexto, a relação entre gênero, sexualidade e discurso fundamentalista religioso é um importante caminho para compreender determinadas opressões vivenciadas por corpos que não são passiveis de reconhecimento, os quais não são reconhecidos como pessoas e não estão inseridos na normalidade.

De tal modo, discurso religioso fundamentalista contribui para reproduzir e manter o mecanismo de gênero fundamentado no binarismo homem x mulher apenas. Além disso, este binarismo e, por sua vez, o preconceito homofóbico/transfóbico está fundamentado em uma crença da verdade divina, a qual para os fundamentalistas cristãos é indiscutível. Sendo assim, normalmente há uma recusa por parte dos fundamentalistas em dialogar sobre questões biológicas, da física, antropológicas, identitárias, dentre outras. Tal recusa se apoia na afirmação de que a Bíblia é um livro que carrega a única verdade possível de se apoiar.

Nesse mar de pensamentos, construções sociais, e ideais, a escola baseia-se em discursos e representações de uma conduta generificada em que as pessoas que não seguem a linearidade sexo, gênero e desejo (Butler, 2003), ou seja, não correspondem à heteronormatividade, são estigmatizadas, focos de olhares, piadas, agressões físicas e verbais. Quando nascem, já são motivadas a desenvolver determinadas práticas, as quais correspondem à norma heterossexual, sutilmente nas brincadeiras, cores e roupas ditas femininas ou masculinas. Assim, desde crianças até a vida adulta são alvo de discursos normatizadores que domesticam seus corpos conforme a norma heterossexual e binária. O que demonstrou-se aqui é que, tal discurso, é fundamentado em um discurso religioso fundamentalista judaico cristão, ultrapassando o espaço igreja e permeando os mais variados espaços cotidianos.

Portanto, é fundamental voltar olhares para fenômenos que estabelecem relação entre as espacialidades instituídas pelos sujeitos através de suas inter-relações, pois tais espacialidades podem se constituir de forma harmoniosa ou conflituosa em decorrência da posição dos sujeitos. Deste modo, a escola, que a partir das falas das travestis que constituem esta pesquisa através de seus relatos de trajetórias de vida, tem ampla significação ao longo de suas vivências, constitui-se de uma espacialidade cuja qual sofrem interdições, sendo marginalizadas/excluídas, causando uma série de efeitos 'cascata' ao longo de suas vidas, de conotação negativa e que ameaçam a dignidade de ser humano, bem como, o bem estar social de cidadãs. Tal efeito, fere diretamente 0 art. 5º da Constituição Federal de 1988, especificamente em seus parágrafos VI, VIII e IX, apresentando-se enquanto ilegítimo, porém também enquanto um enorme efeito contrário à manutenção de vida de sujeitos que não tem sua liberdade assegurada por não corresponderem às matrizes fundamentalistas judaico cristãs.

Para além, esta reflexão buscou estabelecer uma discussão que colabora para a denúncia das práticas que ferem a vida de pessoas que, através de suas vivências, sofrem duras sanções por não corresponderem ao modus hegemônico. Em como o discurso fundamentalista religioso judaico cristão adotado como única verdade, contrariando a laicidade estatal, possivelmente caminha para uma total dissidência inconstitucional à legislação brasileira e, deste modo, apresenta risco à ordem pública e ao direito de liberdade de quaisquer cidadãos, por institucionalizar-se através das entranhas do poder. Por último, a presente pesquisa visa colaborar para o enriquecimento teórico dos campos específicos do saber científico que visam compreender fenômenos sociais, mais especificamente sobre Geografia e Religião.

\section{AGRADECIMENTOS}

Agradecemos à Coordenação de Aperfeiçoamento de Pessoal de Nível Superior (CAPES) por, através da disponibilidade de bolsa de mestrado, colaborou para a viabilização desta reflexão.

\section{REFERÊNCIAS}

ARMSTRONG, Karen. Em nome de Deus - o fundamentalismo no Judaísmo, no Cristianismo e no Islamismo, São Paulo, Companhia da Letras. 2001.

BARDIN, Lawrence. Análise de Conteúdo. Lisboa: Edições 70, 1977. 225 p.

BAUMAN, Zygmunt. Identidade: Entrevista a Benedetto Vecchi. Trad.: Carlos Medeiros.

Rio de Janeiro: Zahar, 2005.

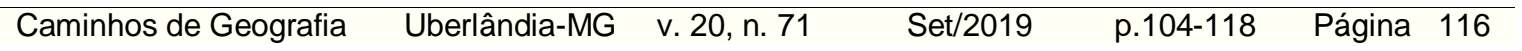


BOFF, Leonardo. Fundamentalismo, terrorismo, religião e paz: desafio para o século XXI. Rio de Janeiro: Vozes, 2009.

BOURDIEU, Pierre. Espaço Social e Espaço Simbólico. In: BOURDIEU, Pierre. Razões práticas: Sobre a teoria da ação. Campinas: Papirus, $9^{\text {a }}$ Ed., 2008, p. 13 - 33.

Brasil. Constituição da República Federativa do Brasil de 1988. Disponível em: <http://www.planalto.gov.br/ccivil_03/Constituicao/Constituicao.htm>. Acesso 23 de setembro de 2018.

BUSIN,Valéria Melki. Religião, Sexualidades e Gênero. REVER-Revista de Estudos da Religião. v. 11, n. 1 2011. https://doi.org/10.21724/rever.v11i1.6032

BUTLER, Judith. Critically Queer. In Playing with Fire: Queer Politics, Queer Theories. Ed. Shane Phelan. New York \& London: Routledge.11-29, 1990.

BUTLER, Judith. Problemas de Gênero: feminismo e subversão da identidade. Rio de Janeiro: Civilização Brasileira, 2003.

Deshacer el Género. Barcelona: Paidós Ibérica, 2006. Cap. 2, p. 67-88.

CIPRIANI, Roberto. Além da Dimensão Institucional, ou melhor, o Papel do Indivíduo na Diatribe entre a Laicidade e a Liberdade Religiosa. In. Debates do NER, Porto Alegre, 2015. https://doi.org/10.22456/1982-8136.56466

CORRÊA, Roberto Lobato. Espaço, Um Conceito-Chave da Geografia. In: Castro, Iná Elias de; GOMES, Paulo Cesar da Costa; CORRÊA, Roberto Lobato (Orgs.). Geografia: Conceitos e Temas. Rio de Janeiro: Bertrand Brasil, 1995, p. $15-47$.

GUIMARÃES, Valtemir Ramos. Fundamentalismo Bíblico Protestante: Abordagem Histórica e Implicações Sociorreligiosas. Dissertação (Mestrado em Ciências da Religião). Universidade Católica de Pernambuco. 2014.

GOMES, Paulo César da Costa. A condição Urbana. Rio de Janeiro: Bertrand Brasil, 2014. 5르 Ed. $304 \mathrm{p}$.

GOUVÊA, Ricardo Quadros. A Piedade Pervertida. São Paulo: Grapho Editores, 2006.

HANKE, Willian; ORNAT, Marcio José; GELINSKI, Adriana. Espaços e vivência interseccional de homens gays na cidade de Ponta Grossa, Paraná. In: IV Simpósio Internacional de Educação Sexual: Feminismos, identidades e politicas públicas. 2015, Maringá. Anais... Maringá: Universidade Estadual de Maringá, 2015.

HEILBORN, Maria Luiza. "Fronteiras simbólicas: gênero, corpo e sexualidade". Cadernos Cepia no 5, Gráfica JB, Rio de Janeiro, 2002.

IBGE. Censo Demográfico. Características gerais da população, religião e pessoas com deficiência. Rio de Janeiro. 2010.

KÜNG, Hans. Projeto de Ética Mundial: uma moral ecumênica em vista da sobrevivência humana. São Paulo: Paulinas, 1993.

LATINOBARÓMETRO. Opinión Pública Latinoamericana. Disponível em:< www.latinobarometro.org >. Acesso em 23 de setembro de 2018.

LIMA, E. L. de. Apresentação. Preparando caminho. A estruturação ética da consciência e a objetivação do real. In: LIMA, E, L. de. Encruzilhadas Geográficas: notas sobre a compreensão do sujeito na teoria social crítica. Rio de Janeiro: Consequência, 2014. p. 07-27; p. 29-75.

LOURO, Guacira Lopes. Um Corpo Estranho: Ensaios Sobre Sexualidade e Teoria Queer. Belo Horizonte: Autêntica, 2004.

MARTY, Martin E.; APPLEBY, R. Scott. Fundamentalisms Observed. Chicago; Londres, 1991.

MASSEY, Doreen B. Pelo Espaço: Uma nova Política da Espacialidade. Rio de Janeiro: Bertrand Brasil, 2008, $312 \mathrm{p}$.

MORAIS, André de. A relação entre moradores e grupo de travestis na instituição de territórios de prostituição no espaço urbano de Ponta Grossa - PR. In: 22ํㅡㄹ Encontro Anual de 
Iniciação Científica. Anais do 22ํㅡㄹ EAIC. Foz do Iguaçu: Universidade Estadual do Oeste do Paraná, 2013. Disponível em: <http://200.201.88.178/portal/pages/anais.php>.

NATIVIDADE, Marcelo Tavares. "Homossexualidade, gênero e cura em perspectivas pastorais evangélicas". Revista Brasileira de Ciências Sociais, 2006. https://doi.org/10.1590/S0102$\underline{69092006000200006}$

Deus me aceita como sou? A disputa sobre o significado da homossexualidade entre evangélicos no Brasil. Tese (Doutorado em Sociologia e Antropologia). Rio de Janeiro: IFICS/UFRJ, 2008.

NATIVIDADE, Marcelo Tavares; OLIVEIRA, Leandro. "Nós Acolhemos os Homossexuais": Homofobia pastoral e Regulação da Sexualidade. Tomo. São Cristovão-SE. no. 2009. https://doi.org/10.21669/tomo.v0i14.504

NOGUÉ, J.; ROMERO, J. Otras Geografías, otros tempos. Nuevas y viejas pregunjas, viejas y nuevas respuestas. In: NOGUÉ, J.; ROMERO, J. (orgs.) Las otras geografias. Valencia: Ed. Tirant la Blanch, 2006. p. 15-50.

ORNAT, Marcio Jose; MORAIS, André de. Instituição de Territórios de Prostituição segundo a relação entre Travestis e Moradores em Ponta Grossa, PR. In: VII Congresso Brasileiro de Geógrafos. Anais do VII CBG. Vitória: Universidade Federal do Espírito Santo, 2014. Disponível em: $<$ http://www.cbg2014.agb.org.br/site/anaiscomplementares?AREA=1>.

ORNELAS, C. V. A. A sedução da intolerância: fundamentalismo e fundamentalismos de um século em construção. Religião \& Cultura, São Paulo, v. 2, n. 3, p. 29-41, jan./jun. 2003.

PANASIEWICZ, Roberlei. Fundamentalismo religioso: história e presencia no cristianismo. In. ALBUQUERQUE, Eduardo Bastos (Org.) Anais do X Simpósio da Associação Brasileira de História das Religiões - "Migrações e Imigrações das Religiões". Assis: ABHR, 2008.

PORCHAT, Patricia. "Conversando sobre psicanálise: entrevista com Judith Butler". Estudos Feministas, Florianópolis: UFSC, vol.18, n.1, pp. 2010. https://doi.org/10.1590/S0104$\underline{026 \times 2010000100009}$

ROSE, Gillian. Performing Space. In: MASSEY, Doreen; ALLEN, John; SARRE, Phillip. Human Geography Today. Cambridge: Polity Press, 1999.

SANTOS, Adelaine Ellis Carbonar. Espaço Escolar, Homossexualidade e Prática Discursiva Docente em Ponta Grossa - PR. Dissertação (Mestrado em Geografia). Universidade Estadual de Ponta Grossa, PR. 2016.

SILVA, A. C. da. As categorias como fundamentos do conhecimento geográfico. In: SANTOS, M; SOUZA, M. A. de (orgs.). O espaço interdisciplinar. São Paulo: Nobel, 1986. p. 25 - 37.

SILVA, Joseli Maria. Cultura e Territorialidades Urbanas - Uma Abordagem da Pequena Cidade. Revista de História Regional, v. 2, n. 5, 2000, p. 9 - 37.

SOUZA. José Arilson Xavier de. Religião: um tema cultural de interesse geográfico. Revista da casa da geografia de sobral. n. 1. 2010.

STREY, Marlene Neves. Psicologia Social Contemporânea. Petrópolis: Vozes, 1998.

TÜRCKE, Christoph. Fundamentalismo. In: DE BONI, Luis Alberto (Org.). Fundamentalismo. Porto Alegre: EDIPUCRS, 1995

WEISS, Raquel Andrade. Do Mundano ao Sagrado: O Papel da Efervescência na Teoria Moral Durkheimiana. Horizontes Antropológicos, Porto Alegre, ano 19, n. 40, p. 395-421, jul./dez. 2013.

Recebido em: 01/10/2018

Aceito para publicação em: 06/02/2019 